\title{
Contaminação por patógenos na alimentação de rua: Revisão sistemática
}

\author{
Contamination by pathogens in street food: Systematic review \\ Contaminación por patógenos en los alimentos de la calle: Revisión sistemática
}

Recebido: 12/07/2021 | Revisado: 17/07/2021 | Aceito: 19/07/2021 | Publicado: 27/07/2021

Hans Fröder
ORCID: https://orcid.org/000-0003-1551-236X
Universidade Estadual do Rio Grande do Sul, Brasil
E-mail: hfroder@ hotmail.com
Márcio Lutero Mafalda Martins
ORCID: https://orcid.org/0000-0001-6403-2069
Universidade Estadual do Rio Grande do Sul, Brasil
E-mail: marcio-martins@ @ergs.edu.br
Wemerson de Castro Oliveira
ORCID: https://orcid.org/0000-0001-7256-265X
Universidade Estadual do Rio Grande do Sul, Brasil
E-mail: wemersoncb@yahoo.com.br
Jaqueline Lidorio de Mattia
Instituto Federal de Educação, Ciência e Tecnologia Sul-rio-grandense, Brasil
ORCID: https://orcid.org/0000-0001-7095-1395
Universidade Estadual do Rio Grande do Sul, Brasil
E-mail: jaqueline-mattia@ uergs.edu.br

\section{Resumo}

Em uma era globalizada, a falta de tempo, a comodidade, as preferências individuais e o próprio estilo de vida das pessoas, fazem com que, a cada ano, o número de refeições consumidas fora de casa cresça. Embora esse movimento seja uma alternativa econômica, essa praticidade fez com que houvesse um aumento no número de surtos alimentares. Essa revisão de literatura tem por objetivo abordar sobre os principais patógenos e problemas encontrados em alimentos comercializados na rua. Os dados das referências apontam que as contaminações de alimentos de rua são frequentes e um risco à saúde pública. É necessário um plano de intervenções e capacitações dos vendedores ambulantes, quanto a higienização correta de todos os processos de produção, para garantir a segurança alimentar dos consumidores. Além disso, uma estrutura básica adequada para o vendedor é essencial para priorizar a qualidade na oferta dos alimentos.

Palavras-chave: Surtos alimentares; Alimentos; Manipuladores; Saúde pública.

\begin{abstract}
In a globalized era, the lack of time, convenience, individual preferences and people's own lifestyles, mean that, each year, the number of meals eaten outside the home grows. Although this movement is an economic alternative, this practicality has caused an increase in the number of food outbreaks. This literature review aims to address the main pathogens and problems found in street foods. Reference data indicate that street food contamination is frequent and a risk to public health. A plan of interventions and training of street vendors is needed, regarding the correct hygiene of all production processes, to ensure food safety for consumers. Furthermore, an adequate basic structure for the seller is essential to prioritize the quality of food supply.
\end{abstract}

Keywords: Food outbreaks; Food; Handlers; Public health.

\section{Resumen}

En una era globalizada, la falta de tiempo, la comodidad, las preferencias individuales y los estilos de vida propios de las personas, hacen que, cada año, el número de comidas que se consuman fuera del hogar crezca. Aunque este movimiento es una alternativa económica, esta practicidad ha llevado a un aumento en el número de brotes alimentarios. Esta revisión de la literatura tiene como objetivo abordar los principales patógenos y problemas encontrados en los alimentos que se venden en la vía pública. Los datos de referencia indican que la contaminación de los alimentos en la vía pública es frecuente y un riesgo para la salud pública. Es necesario un plan de intervenciones y formación de los vendedores ambulantes, en cuanto a la correcta higiene de todos los procesos productivos, para garantizar la seguridad alimentaria de los consumidores. Además, una estructura básica adecuada para el vendedor es fundamental para priorizar la calidad del suministro de alimentos.

Palabras clave: Brotes alimentarios; Alimentos; Manipuladores; Salud pública. 


\section{Introdução}

O termo "comida de rua" vem sendo utilizado para designar alimentos e bebidas comercializados em vias públicas, destinados ao consumo imediato ou posterior, sem necessidade de um preparo adicional (Cardoso et al., 2009). Cada vez mais habitual, o consumo de alimentos de rua tem-se tornado uma opção prática e econômica para a população, porém, as preocupações sobre a segurança destes alimentos são cada vez maiores. Segundo Rane (2011), as maiores fontes que contribuem para a contaminação microbiana são o local de preparo, utensílios para cozinhar e servir, abuso de produtos in natura, tempo e temperatura de cocção e a higiene pessoal dos vendedores.

A ocorrência de doenças transmitidas por alimentos (DTA) é um problema relevante para a saúde pública, uma vez que se tem um impacto negativo tanto no contexto social, em decorrência das vítimas que sofrem os agravos, quanto no econômico, onde as perdas são geradas nos ramos da indústria, comércio e turismo. Ainda, para muitas pessoas, este é um assunto tratado de forma irrelevante ou até mesmo desconhecido, o que torna o problema ainda maior (Melo et al., 2018). A maioria desses obstáculos pode ser controlada com os esforços por parte dos próprios manipuladores de alimentos, seja em uma planta de processamento, um restaurante, uma feira, entre outros, adotando práticas higiênicas-sanitárias corretas e seguras.

Em uma pesquisa conduzida por Bezerra (2017), empregando os dados da pesquisa de Orçamento Familiar 2008-2009, avaliaram 152.895 indivíduos, com idade acima de 10 anos, sobre os locais de aquisição dos alimentos consumidos fora de casa. Os resultados revelaram que $41,2 \%$ dos entrevistados adquiriam seus alimentos fora do lar, sendo a maior porcentagem (44\%) do sexo masculino contra 38,5\% do feminino. Os adultos apresentaram maior frequência de aquisição (46\%) comparados com os adolescentes $(37,7 \%)$ e os idosos $(24,2 \%)$. Os locais mais frequentados pelos os respondentes foram lanchonete $(16,9 \%)$ e restaurante $(16,4 \%)$, enquanto frutaria $(1,2 \%)$ apresentou a menor porcentagem. Os industrializados como doces, salgadinhos e refrigerantes foram os alimentos mais adquiridos na maioria dos locais. Frente a isso, este trabalho de revisão sistemática tem por objetivo abordar sobre os principais patógenos encontrados em alimentos comercializados na rua, às práticas de higiene dos manipuladores e os impactos que podem causar na saúde coletiva.

\section{Metodologia}

A pesquisa, a partir de seu objetivo, caracteriza-se como qualitativa (Estrela, 2018) e apresenta o delineamento do tipo análise de documentos (Mayring, 2002). Esse último autor ainda afirma que a pesquisa qualitativa "apresenta seis delineamentos da pesquisa qualitativa: estudo de caso, análise de documentos, pesquisa-ação, pesquisa de campo, experimento qualitativo e avaliação qualitativa" (p.204). Neste tipo de delineamento além de procedimentos tradicionais, como leitura e resumo de ideias, é possível extrair e sumarizar resultados por meio de meta-análise (Günther, 2006). Além disso, Günther (2006) ainda cita que "dependendo da natureza dos documentos, existem as mais diferentes maneiras de encará-los, desde relatos verbais e respostas a perguntas de pesquisadores futuros, até segmentos de texto selecionados como "sujeitos" entre um corpo linguístico grande, por meio de procedimentos de amostragem".

Os artigos considerados elegíveis para inclusão nesta revisão, foram aqueles que apresentaram estudos originais referentes à temática, publicados em inglês e em português, no período compreendido entre os anos 2009 a 2021, empregando os seguintes descritores "alimentos", "rua", "manipuladores" e "patógenos". Os termos foram cruzados um com o outro para conseguir maior abrangência e relevância dos resultados. Os artigos identificados pela estratégia de busca foram avaliados de forma independente. $\mathrm{O}$ estágio inicial de seleção do artigo incluiu a análise do título, depois a análise do resumo e, finalmente, um estudo de leitura completo para verificar os critérios de elegibilidade. Os documentos não originais foram excluídos (editoriais, cartas, comentários, capítulos de livros e livros) e os selecionados foram baixados através das plataformas eletrônicas PubMed, Google Acadêmico, Science Direct, entre outras. Artigos selecionados para a revisão sistemática foram avaliados 
quanto à qualidade do estudo de uma forma sistemática e transparente. O julgamento de qualidade é, assim, derivado através de um conjunto de questões metodológicas pensadas anteriormente e aplicadas a todos os estudos em questão. Para os fins do presente estudo, perguntas foram escolhidas para a avaliação da qualidade como: adequação do tema; questão de pesquisa; rigor nas medidas de pesquisa; e fatores de confusão (Baglioni et al. 2016).

\section{Resultados e Discussão}

Apesar da grande importância das DTA e o impacto que causam na saúde pública, ainda são reduzidos os números de trabalhos científicos que avaliam e abordam esse tema, totalizando 21 neste estudo. Um estudo de revisão conduzido por Finger et al. (2019) avaliou os surtos e as DTA notificadas no Brasil entre 2000 e 2018, usando os dados oficiais do Ministério da Saúde. Os pesquisadores identificaram 13.163 surtos, envolvendo 247.570 casos e 195 mortes, com a região sudeste apresentando a maior prevalência de surtos $(45,6 \%)$. O gênero Salmonella $(14,4 \%)$ foi o patógeno mais identificado e o local de ocorrência foi na própria residência $(12,5 \%)$ através da ingestão de alimentos mistos $(31,6 \%)$. Os pesquisadores destacam que a notificação de surtos é essencial para a tomada de ações.

A contaminação dos alimentos com patógenos/toxinas e sua persistência e multiplicação emergiu como uma importante preocupação de saúde pública. Segundo Hassanaian et al. (2013), os agentes patogênicos de origem alimentar causam uma carga e um desafio considerável para a saúde pública, principalmente para os grupos de risco que incluem recém-nascidos, gestantes, idosos e pessoas com o sistema imunológico comprometido. Eles mencionam que em países menos desenvolvidos, as doenças diarreicas, causadas pelos alimentos ou água, ainda são as responsáveis pela morte de milhões de pessoas a cada ano. Mesmo em países desenvolvidos, estima-se anualmente, que até um terço da população seja acometida por alguma DTA. A maioria dos patógenos que causam essa carga significativa de doenças provém das zoonoses, sendo a principal fonte os alimentos crus ou mal cozidos. Além disso, os manipuladores de alimentos desempenham um papel importante na garantia da segurança alimentar em toda a cadeia produtiva de alimentos. As infecções de origem alimentar mais comumente conhecidas são aquelas causadas por bactérias, incluindo Campylobacter spp., Escherichia coli O157:H7, Salmonella spp., Listeria monocytogenes, Staphylococcus aureus; vírus da hepatite A, rotavírus, entre outras.

Ainda para Hassanaian et al. (2013), a prevenção das DTA exige a aplicação de sistemas de vigilância e informação. Além disso, é necessária a aplicação do sistema de gestão de análise de perigos e pontos críticos de controle (HACCP) em toda a cadeia produtiva de alimentos (do campo à mesa), com regulamentações de importação/exportação. Os autores supracitados destacam, por exemplo, que a redução da contaminação microbiológica da carne pode ser obtida através de higiene ambiental, inspeção obrigatória do rebanho e de normas sanitárias em matadouros e plantas de processamento. Além disso, a segurança alimentar também pode ser alcançada aplicando higiene pessoal, higienização das instalações e utensílios de cozinha. Destacam que o planejamento de programas de educação em saúde para manipuladores de alimentos e consumidores, são regras essenciais para prevenir as DTA.

Um estudo sobre o perfil de vendedores ambulantes e as práticas de higiene utilizadas na produção de alimentos foi conduzido por Cortese et al. (2016) em Florianópolis/SC. Esses pesquisadores fizeram observações e entrevistas com 43 vendedores em diferentes pontos no centro da cidade. O estudo revelou que $95 \%$ manipulam alimentos e dinheiro, sem higienizar as mãos, e 65\% afirmaram lavar as mãos durante a atividade. A frequência de higienização foi baixa, com média de quatro vezes ao dia, sendo que $24 \%$ utilizavam apenas água. Embora o município tenha uma lei que exige a obrigatoriedade de treinamento sobre práticas higiênicas para os manipuladores de alimentos, $33 \%$ dos vendedores não tinham passado pela capacitação. Salientam ainda a necessidade de uma infraestrutura básica adequada ao vendedor, priorizando assim, a segurança e a qualidade dos alimentos.

Em uma pesquisa similar realizada por Monteiro et al. (2017), em Belo Horizonte/MG, analisaram a qualidade 
microbiológica de alimentos comercializados por camelôs. A pesquisa compreendeu 51 vendedores ambulantes com faixa etária média de 41 anos, sendo que destes, 48 responderam ao questionário socioeconômico e lista de verificação; 50, para a medição da temperatura dos alimentos; e cinco, para análise microbiológica (alimentos, utensílios e mãos). Considerando as não conformidades, 43,8\% dos vendedores não usavam boné ou touca; 87,5\% manuseiam dinheiro na manipulação dos alimentos; e apenas $18,7 \%$ dos alimentos quentes exibiram temperaturas em conformidade com o padrão previsto na legislação (Brasil, 2004). Os microrganismos detectados nas amostras de alimentos foram bactérias aeróbias mesófilas viáveis $(100 \%)$, coliformes a $35^{\circ} \mathrm{C}$ (60\%), Staphylococcus aureus (60\%), Bacillus cereus (20\%) e Salmonella spp. (60\%). Todas as amostras de utensílios indicaram má-higiene, o que exige a necessidade de uma legislação sanitária específica para este tipo de negócio.

A qualidade microbiológica de 105 hambúrgueres e as mãos de vendedores ambulantes foram avaliados em Cuiabá/MT por Bezerra et al. (2010). O total de 31,4\% das amostras de hambúrguer estavam inadequadas para o consumo, com resultados positivos para coliformes e estafilococos coagulase positiva em níveis elevados aos da legislação vigente. As mãos dos manipuladores atingiram populações de mesófilos aeróbios em níveis de 1,8 x 10 $0^{4} \mathrm{UFC} / \mathrm{mão}$. Através de questionários os pesquisadores avaliaram o nível de conscientização quanto às práticas aceitáveis de manipulação de alimentos e verificaram que $80 \%$ dos vendedores nunca haviam participado de qualquer tipo de treinamento.

Inoue e Lopes (2016) realizaram um estudo de revisão de literatura onde o objetivo foi avaliar a produção científica sobre a comida de rua e seu controle higiênico-sanitário, no período de 2001 a 2012, analisando as estratégias com vistas à segurança do consumidor. A investigação sobre hambúrgueres revelou achados positivos, principalmente quanto à sua qualidade microbiológica, pois 99\% deles estavam de acordo com os padrões da legislação em vigor. No entanto, destacam que a maioria dos estudos avaliados contrariam as boas práticas de manipulação e produção de alimentos.

No Quadro 1, encontram-se alguns estudos em que o objetivo dos pesquisadores era avaliar as condições higiênicosanitárias de alimento, da embalagem, dos utensílios/mesas, dos manipuladores e da estrutura onde o alimento é comercializado à população. Os achados desses estudos revelam uma situação precária na higiene e a falta de cuidado na manipulação do alimento. Fica evidente que se faz necessário o desenvolvimento de ações para a qualificação profissional dos comerciantes de comida de rua, uma vez que há aumento desse tipo de alimento.

Um estudo transversal, observacional realizado por Silva (2016), avaliou as condições higiênico-sanitárias de vendedores ambulantes de alimentos em Brasília, DF. Eles utilizaram um check-list com base na legislação sanitária federal RDC $n^{\circ}$ 216/2004, onde realizaram coletas, através da técnica de $s w a b$, em 10 amostras das mãos de vendedores. Todos os manipuladores foram submetidos à pesquisa de coliformes termotolerantes, Staphylococcus sp. e bactérias mesófilas anaeróbias. O uso de adornos foi observado em 8 (80\%) dos manipuladores, e a presença de barba, bigode, unhas grandes e ausência de touca em $6(60 \%)$ dos vendedores. A presença de microrganismos mesófilos foi evidenciada em 9 (90\%) manipuladores, de Staphylococcus sp. em 7 (70\%) e coliformes termotolerantes nas mãos de $5(50 \%)$ vendedores de rua. Essa mesma percepção, que a venda ambulante é uma fonte potencial de disseminação de DTA, foi apontada por Ferrari et al. (2021). 
Quadro 1. Estudos com avaliação higiênico-sanitária de alimentos, de embalagem, dos utensílios/mesas, dos manipuladores e da estrutura de comercialização.

\begin{tabular}{|c|c|c|c|}
\hline CIDADE & OBJETIVO & ACHADOS & REFERÊNCIA \\
\hline Campo Mourão (PR) & $\begin{array}{l}\text { Avaliar as condições microbiológicas de molho verde e suas } \\
\text { embalagens provenientes de delivery, comercializados por } \\
\text { ambulantes. Foram avaliadas } 15 \text { amostras de molho verde e suas } \\
\text { embalagens, realizando análise de Staphylococcus aureus e } \\
\text { Escherichia coli nas embalagens de molho por meio de swab }\end{array}$ & $\begin{array}{l}\text { O total de } 14 \text {, das } 15 \text { amostras analisadas de molhos verdes estavam } \\
\text { dentro dos padrões de qualidade estabelecida pela legislação vigente, } \\
\text { porém com indícios de falha nas boas práticas, principalmente no } \\
\text { serviço de delivery realizado por ambulantes }\end{array}$ & Silveira, 2020 \\
\hline $\begin{array}{l}\text { Mutuípe e Santo Antônio } \\
\text { de Jesus (BA) }\end{array}$ & $\begin{array}{l}\text { Caracterizar o perfil social e as condições higiênico-sanitárias do } \\
\text { comércio de alimentos }\end{array}$ & $\begin{array}{l}\text { O diagnóstico higiênico-sanitário permitiu a classificação do maior } \\
\text { percentual dos pontos de venda como "ruim" (56,3\%), pois } \\
\text { apresentavam percentual de adequação dos itens do checklist menor } \\
\text { que } 50 \% \text { conforme classificação estabelecida na RDC n }{ }^{\circ} 275: 2002\end{array}$ & Santos e Silva 2019 \\
\hline Porto Alegre (RS) & $\begin{array}{l}\text { Avaliar as condições higiênico-sanitárias dos ambulantes que } \\
\text { comercializam cachorro-quente, através da coleta de uma } \\
\text { amostra do produto em } 20 \text { pontos de venda }\end{array}$ & $\begin{array}{l}\text { Total de } 75 \% \text { apresentaram positividade para coliformes totais, } 30 \% \\
\text { para coliformes fecais e } 25 \% \text { para Staphylococcus coagulase positiva }\end{array}$ & Kothe, 2014 \\
\hline Rio de Janeiro (RJ) & $\begin{array}{l}\text { Avaliar as condições higiênico-sanitárias e o perfil da } \\
\text { comunidade microbiana dos utensílios e das mesas de um } \\
\text { serviço de alimentação. Foram analisadas } 126 \text { amostras } \\
\text { higienizadas (utensílios: n=90 e mesas: n=36). Pesquisaram-se } \\
\text { bactérias mesófilas, coliformes, Escherichia coli, } \\
\text { Staphylococcus aureus e fungos }\end{array}$ & $\begin{array}{l}\text { Das amostras analisadas, } 100 \% \text { dos utensílios e } 80 \% \text { das mesas } \\
\text { apresentaram contagens microbianas superiores ao recomendado na } \\
\text { literatura, estando em condições higiênico-sanitárias inadequadas. } E \text {. } \\
\text { coli foi isolada nos utensílios e S. aureus nas mesas }\end{array}$ & Oliveira et al., 2019 \\
\hline Salvador (BA) & $\begin{array}{l}\text { Caracterizar o comércio de comida de rua no circuito } \\
\text { carnavalesco do campo grande, Salvador-BA, realizado junto a } \\
264 \text { vendedores, com aplicação de formulários semiestruturados, } \\
\text { preenchidos por meio de entrevista e observação in loco }\end{array}$ & $\begin{array}{l}\text { Observaram-se alimentos e bebidas em contato com o solo }(30,1 \%) \text {, } \\
\text { manipulação concomitante de alimentos e dinheiro }(34,3 \%) \text {, além da } \\
\text { finalização de produtos }(17,4 \%) \text {. Os vendedores referiram lavar as } \\
\text { mãos mais de cinco vezes ao dia }(54,9 \%) \text { e os utensílios }(26,1 \%) \text {, } \\
\text { equipamentos, ponto de venda e/ou ambiente }(42,8 \%) \text {, uma vez ao dia, } \\
\text { considerando as condições de risco potencial associado à saúde } 48,5 \% \\
\text { dos pontos de venda foram classificados como de alto risco, } 39,8 \% \\
\text { como de médio risco e } 11,7 \% \text { como baixo risco }\end{array}$ & Santos, 2011 \\
\hline Salvador (BA) & $\begin{array}{l}\text { Caracterizar o comércio de comida de rua na orla de Salvador- } \\
\text { BA, sob a perspectiva socioeconômica, do trabalho e da } \\
\text { segurança de alimentos }\end{array}$ & $\begin{array}{l}\text { Apenas } 33,8 \% \text { dos alimentos perecíveis eram conservados em caixas } \\
\text { isotérmicas. Entre os } 247 \text { entrevistados, } 22,6 \% \text { disseram não } \\
\text { higienizar as mãos durante o trabalho, enquanto, } 80,2 \% \text { manipulavam } \\
\text { alimento e dinheiro simultaneamente }\end{array}$ & Santos, 2012 \\
\hline
\end{tabular}

Fonte: Autores. 
Em outra pesquisa também do tipo transversal, observacional e descritiva realizada de julho de 2016 a março de 2017, os pesquisadores usaram listas de verificação de boas práticas com base na legislação e concluíram que os lugares visitados apresentaram adequação média igual a 44\%, a partir da análise dos checklists, apontando para a necessidade de melhorias, principalmente em relação ao licenciamento sanitário e condições ambientais (Oliveira; São José, 2019).

Algumas legislações tratam de forma abrangente o assunto, incluindo a Portaria SVS/MS n 326, que define as condições higiênico-sanitárias e de boas práticas de fabricação para a indústrias de alimentos e a RDC n 216 da Agência Nacional de Vigilância Sanitária (Anvisa), que dispõe sobre regulamento técnico de boas práticas para serviços de alimentação. Esses serviços devem dispor de manual de boas práticas de fabricação (BPF), documentos acessíveis aos funcionários envolvidos e disponíveis à autoridade sanitária. Além disso, os manipuladores de alimentos deveriam se informar sobre as legislações estaduais e municipais antes de ingressarem nesse ramo de atividade. O Centro Estadual de Vigilância em Saúde (CEVS) do Rio Grande do Sul, por exemplo, tem na sua página da internet as principais legislações sobre a vigilância em alimentos.

Oliveira et al. (2015) verificou as condições de boas práticas de higiene e manipulação (BPHM) e de infraestrutura (IE) de oito restaurantes/lanchonetes e de sete pontos de comércio ambulante de uma cidade universitária por meio de abordagem exploratória e qualitativa aplicando listas de verificação. Os ambulantes analisados apresentaram melhores resultados no cumprimento das normas de BPHM e IE quando comparados aos estabelecimentos fixos de comércio alimentício. Os pesquisadores constataram que é possível a prática do comércio de alimentos de rua com qualidade, sem caracterizar uma ameaça à saúde pública.

A aplicação de lista de verificação também permite a avaliação de risco das práticas e condições higiênico-sanitárias em food trucks e, potencialmente, garante o acesso dos consumidores a comida de rua segura (Isoni Auad et al., 2018). No caso, a lista foi projetada com base no Codex Alimentarius, Resolução RDC n 216, Resolução RDC n 275 e legislações estadual e municipal específicas do Distrito Federal, sendo a versão final do instrumento composta por 39 itens. Os autores sugerem que a lista de verificação pode ser usada para realizar inspeções em food trucks por auditores de vigilância sanitária, dos processos de tomada de decisão dos vendedores, e também como ferramenta de diagnóstico.

\section{Considerações Finais}

Os alimentos de rua possuem importância econômica e cultural para a população de diferentes países, principalmente aqueles em desenvolvimento como é o caso do Brasil, e sua qualidade pode ser afetada por condições ambientais e pela forma como são manipulados. A maioria dos resultados das citações realizadas neste estudo demonstram que as condições higiênicosanitárias dos vendedores ambulantes são insatisfatórias, sendo necessárias medidas de intervenção junto a esses manipuladores, além de treinamento e maior fiscalização nos locais de comercialização.

Os bons resultados obtidos nos trabalhos em que foram realizadas listas de verificação é uma visão interessante para melhoria da qualidade da alimentação de rua. Isso revela que as organizações (secretarias, prefeituras, universidades, associações, serviços de apoio a pequenas empresas, etc.) devem oferecer programas de educação para vendedores ambulantes de alimentos e assim, contribuir com práticas de higiene adequadas.

Diante ao exposto, para minimizar os riscos, muitas cidades já possuem uma lei municipal que regulamenta a venda e a doação de alimentos nas ruas e em outras áreas públicas. Aliado a isso, a vigilância sanitária municipal pode exigir, quando necessário, que os manipuladores de alimentos, na modalidade gastronomia itinerante, apresentem o certificado de participação em curso de boas práticas em serviços de alimentação. Isso é essencial para melhorar a qualidade dos alimentos vendidos nas ruas e a prevenção de doenças de origem alimentar.

Trabalhos futuros envolvendo incentivos aos manipuladores na busca contínua por cursos na área, a disponibilização 
de uma infraestrutura adequada, ainda, a elaboração e a implementação do checklist para monitorar as práticas higiênicas seguras, são questões que poderiam ser mais exploradas. Além disso, é necessário ampliar esse tipo de pesquisa para avaliar os pontos críticos em estabelecimentos de rua, uma vez que o índice de intoxicação alimentar não é preciso pela falta de diagnóstico, promovendo assim, uma melhor análise de ocorrências das DTA no Brasil.

\section{Referências}

Auad, L. I., Ginani, V. C., Leandro, E. S., Farage, P., Nunes, A. C. S., \& Zandonadi, R. P. (2018). Development of a Brazilian food truck risk assessment instrument. International Journal of Environmental Research and Public Health, 15 (12), 2624. https://doi.org/10.3390/ijerph15122624

Baglioni C., Nissen C., Schweinoch A. \& Riemann D. (2016). Polysomnographic Characteristics of Sleep in Stroke: A Systematic Review and Meta- -Analysis. PLoS One 1:1-23. https://doi.org/10.1371/journal.pone.0148496.

Bezerra, I. N., Moreira, T. M. V. Cavalcante, J. B., Souza, A. D. M., \& Sichieri, R. (2017). Consumo de alimentos fora do lar no Brasil segundo locais de aquisição. Revista de Saúde Pública, 51 (15), 1-8. https://doi.org/10.1590/S1518-8787.2017051006750

Bezerra, A. C. D., Reis, R. B. D., \& Bastos, D. H. M. (2010). Microbiological quality of hamburgers sold in the streets of Cuiabá-MT, Brazil and vendor hygieneawareness. Food Science and Technology, 30 (2), 520-524. https://doi.org/10.1590/S0101-20612010000200035

Brasil. Ministério da Saúde. Portaria No 326, de 30 de julho de 1997. Regulamento técnico sobre as condições higiênico-sanitárias e de boas práticas de fabricação para estabelecimentos produtores/industrializadores de alimentos. https://bvsms.saude.gov.br/bvs/saudelegis/svs1/1997/prt0326_30_07_1997.html.

Brasil. Ministério da Saúde. Resolução $N^{\circ} 216$, de 15 de setembro de 2004. Regulamento técnico de boas práticas para serviços de alimentação. https://bvsms.saude.gov.br/bvs/saudelegis/anvisa/2004/res0216_15_09_2004.html.

Brasil. Ministério da Saúde. Resolução de Diretoria Colegiada-RDC No 275, de 21 de outubro de 2002. Dispõe sobre o Regulamento Técnico de Procedimentos Operacionais Padronizados aplicados aos Estabelecimentos Produtores/Industrializadores de Alimentos e a Lista de Verificação das Boas Práticas de Fabricação em Estabelecimentos Produtores/Industrializadores de Alimentos. https://www.gov.br/agricultura/pt-br/assuntos/inspecao/produtos-vegetal/legislacao1/biblioteca-de-normas-vinhos-e-bebidas/resolucao-rdc-no-275-de-21-de-outubro-de-2002.pdf/view.

Cardoso, R. D. C. V., Santos, S. M. C. D., \& Silva, E. O. (2009). Comida de rua e intervenção: estratégias e propostas para o mundo em desenvolvimento. Ciência \& Saúde Coletiva, 14(4), 1215-1224. https://doi.org/10.1590/S1413-81232009000400027

Cortese, R. D. M., Veiros, M. B., Feldman, C., \& Cavalli, S. B. (2016). Food safety and hygiene practices of vendors during the chain of street food production in Florianópolis, Brazil: A cross-sectional study. Food Control, 62, 178-186. https://doi.org/10.1016/j.foodcont.2015.10.027

Ferrari, A. M., Oliveira, J. D. S. C., \& São José, J. F. B. D. (2021). Street food in Espírito Santo, Brazil: a study about good handling practices and food microbial quality. Food Science and Technology, Ahead of Print, 01-08. https://doi.org/10.1590/fst.31620

Finger, J. A., Baroni, W. S., Maffei, D. F., Bastos, D. H., \& Pinto, U. M. (2019). Overview of foodborne disease outbreaks in Brazil from 2000 to 2018. Foods, 8(10), 434-444. https://doi.org/10.3390/foods8100434

Günther, H. (2006). Pesquisa qualitativa versus pesquisa quantitativa: esta é a questão? Psicologia: teoria e pesquisa, 22, 201-209. https://doi.org/10.1590/S0102-37722006000200010

Inoue, Y. F. P., \& Lopes, A. C. M. (2016). Comida de Rua e Grandes Eventos: Boas Práticas de Manipulação e Controle e Sanitário. Higiene Alimentar, 30, 254-255. https://docs.bvsalud.org/biblioref/2016/12/827311/separata-32-36.pdf

Hassanain, N. A., Hassanain, M. A., Ahmed, W. M., Shaapan, R. M., Barakat, A. M., \& El-Fadaly, H. A. (2013). Public health importance of foodborne pathogens. World Journal of Medical Sciences, 9 (4), 208-222. https://doi.org/10.5829/idosi.wjms.2013.9.4.8177

Kothe, C. I., Schild, C. H., Tondo, E. C., \& Da Silva Malheiros, P. (2016). Microbiological contamination and evaluation of sanitary conditions of hot dog street vendors in Southern Brazil. Food Control, 62, 346-350. https://doi.org/10.1016/j.foodcont.2015.11.005

Magalhães Monteiro, M. A., Dutra, D. B., Torres, F. A., De Oliveira, R. B. P., Ribeiro, R. D. C., \& Teixeira Garcia, M. A. V. (2017). Microbiological quality of street foods in Belo Horizonte, Minas Gerais. Demetra: Food, Nutrition \& Health/Alimentação, Nutrição \& Saúde, 12 (3), $781-794$.

Mayring, P.h. (2002). Einführung in die qualitative Sozialforschung [Introdução à pesquisa social qualitativa]. (5a ed.). Weinheim: Beltz.

Melo, E. S., De Amorim, W. R., Pinheiro, R. E. E., Do Nascimento Corrêa, P. G., De Carvalho, S. M. R., Santos, A. R. S. S., \& De Sousa, F. V. (2018). Doenças transmitidas por alimentos e principais agentes bacterianos envolvidos em surtos no Brasil. PUBVET, 12, 131. https://doi.org/10.31533/pubvet.v12n10a191.1-9

Oliveira, T. H. N., Junior, E. D. B. C., Ribeiro, N. A. S., Assi, A. L., De Abreu, R. A. F., Martins, W. S., ... \& De Carvalho Balian, S. (2015). Comércio de alimentos na Universidade de São Paulo: avaliação das condições higiênico-sanitárias e infraestrutura. Vigilância Sanitária em Debate: Sociedade, Ciência \& Tecnologia, 3 (4), 91-98. https://doi.org/10.3395/2317-269x.00485

Oliveira, A. G. D. M. D., Melo, L., Gomes, D. B. C., Peixoto, R. S., Leite, D. C. D. A., Leite, S. G. F., \& Miguel, M. A. L. (2019). Condições higiênico-sanitárias e perfil da comunidade microbiana de utensílios e mesas higienizadas de um serviço de alimentação localizado no Rio de Janeiro. Brazilian Journal of Food Technology, 22. https://doi.org/10.1590/1981-6723.09718 
Research, Society and Development, v. 10, n. 9, e33210918177, 2021

(CC BY 4.0) | ISSN 2525-3409 | DOI: http://dx.doi.org/10.33448/rsd-v10i9.18177

Oliveira, J. D. S. C., \& De São José, J. F. B. (2019). Food handling practices and microbial quality in street food. Journal of Food and Nutrition Research, 7 (4), 319-324. https://doi.org/10.12691/jfnr-7-4-9

Rane, S. (2011). Street vended food in developing world: hazard analyses. Indian Journal of Microbiology, 51 (1), 100-106. https://doi.org/10.1007/s12088011-0154-x

Santos, K. B. (2011). O comércio da comida de rua no carnaval de Salvador-BA: desvendando as dimensões social, econômica, alimentar e sanitária. Dissertação (mestrado) - Programa de Pós-Graduação em Alimentos, Nutrição e Saúde (PGNUT) - Universidade Federal da Bahia, Salvador, BA. https://repositorio.ufba.br/ri/handle/ri/10493.

Santos, T. D. J. S. D., \& Silva, I. D. M. M. D. (2019). Características sociais e sanitárias do comércio de comida de rua na perspectiva da segurança dos alimentos. Monografia (graduação) - Centro de Ciências da Saúde - Universidade Federal do Recôncavo da Bahia, Santo Antônio de Jesus, BA. http://200.128.85.17/bitstream/123456789/1501/1/Trabalho\%20de\%20Conclus\%C3\%A3o\%20de\%20Curso-\%20Thays\%20de\%20Jesus\%20Sodr\%C3\%A9\%2 0dos\%20Santos.pdf.

Silva, S. (2012). A comida de rua na orla de Salvador-BA: um estudo na perspectiva socioeconômica e da segurança de alimentos. Dissertação (mestrado) Programa de Pós-Graduação em Alimentos, Nutrição e Saúde (PGNUT) - Universidade Federal da Bahia, Salvador, BA. https://repositorio.ufba.br/ri/handle/ri/10421

Silveira, J. N. (2020). Avaliação microbiológica de molhos verdes e suas embalagens provenientes de delivery, comercializados por ambulantes de alimentos na cidade de Campo Mourão-Paraná. Monografia (graduação) - Departamento Acadêmico de Alimentos - Universidade Tecnológica Federal do Paraná, Campo Mourão, PR. http://repositorio.utfpr.edu.br/jspui/handle/1/23919. 